\title{
Placental Abruption after Fetoscopic Laser Surgery in Twin-Twin Transfusion Syndrome: The Role of the Solomon Technique
}

\author{
Patricia J.C. Knijnenburg ${ }^{a} \quad$ Enrico Lopriore $^{a}$ Yuchun Ge $^{b}$ Irene M. Scholl ${ }^{c}$ \\ Jeanine M.M. van Klink ${ }^{d}$ Monique C. Haak ${ }^{c}$ Johanna M. Middeldorp ${ }^{c}$ \\ Frans J.C.M. Klumper ${ }^{c}$ Dick Oepkes ${ }^{c}$ Luming Sun ${ }^{b}$ Femke Slaghekke ${ }^{c}$ \\ aDivision of Neonatology, Department of Pediatrics, Leiden University Medical Center, Leiden, The Netherlands; \\ ${ }^{b}$ Department of Fetal Medicine \& Prenatal Diagnosis Center, Shanghai 1st Maternity and Infant Hospital of Tongji \\ University, Shanghai, China; 'Division of Fetal Medicine, Department of Obstetrics, Leiden University Medical

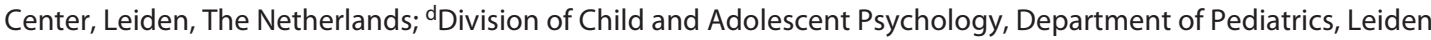 \\ University Medical Center, Leiden, The Netherlands
}

\section{Keywords}

Twin-twin transfusion syndrome · Fetoscopic laser surgery · Placental abruption

\begin{abstract}
Introduction: Twin-twin transfusion syndrome (TTS) is a complication in monochorionic twin pregnancies which is preferably treated with fetoscopic laser surgery. A few small studies suggested a possible association between the Solomon laser technique and placental abruption. Methods: The objective of this study is to compare the rate of and to explore potential risk factors for placental abruption in TTTS treated with fetoscopic laser surgery according to the Selective and Solomon laser technique. We conducted a large retrospective cohort study of consecutive TTTS-cases treated with fetoscopic laser surgery in Shanghai, China, and Leiden, The Netherlands treated with either the Selective laser technique (Selective group) or Solomon laser technique (Solomon group). Results: The rate of placental abruption in the Selective group versus the Solomon group was $1.7 \%(5 / 289)$ and $3.4 \%(15 / 441)$, respectively $(p=0.184)$. No risk factors for placental abruption were identified. Placental abruption was associated with lower gestational age at birth $(p=0.003)$
\end{abstract}

karger@karger.com www.karger.com/fdt

Karger!"

BOPEN ACCESS
(C) 2021 The Author(s)

Published by S. Karger AG, Basel

This is an Open Access article licensed under the Creative Commons Attribution-NonCommercial-4.0 International License (CC BY-NC) (http://www.karger.com/Services/OpenAccessLicense), applicable to the online version of the article only. Usage and distribution for commercial purposes requires written permission. and severe cerebral injury $(p=0.003)$. Conclusion: The prevalence of placental abruption in TTS after fetoscopic laser surgery is low, although it appears higher than in the overall population. Placental abruption is associated with a lower gestational age at birth, which is associated with severe cerebral injury. The rate of placental abruption was not significantly increased with the use of the Solomon technique. Continued research of placental abruption in TTS is necessary to determine why the rate is higher than in the overall population.

(c) 2021 The Author(s)

Published by S. Karger AG, Basel

\section{Introduction}

Twin-twin transfusion syndrome (TTTS) affects approximately $10 \%$ of all monochorionic twin pregnancies [1]. The preferred treatment is fetoscopic laser surgery to separate the blood circulations of the twins by coagulating all inter-twin anastomoses on the placenta. Two different techniques are available to separate the fetal circulations: in the Selective technique, all inter-twin anastomoses at the placental surface are identified and coagulated; whereas in the Solomon technique, after co- 
agulation of the individual anastomoses, an additional line is coagulated on the placental surface, from 1 edge of the placenta to the other along the vascular equator, connecting all individual laser spots. The Solomon trial showed a significant reduction in the prevalence of postlaser twin anemia polycythemia sequence and recurrent TTTS when the Solomon technique was used [2]. Other complications including premature rupture of membranes, infection, and iatrogenic monoamnionicity were comparable between the techniques [2]. A lesser-known complication is placental abruption. Placental abruption is the preterm detachment of the placenta from the uterine wall characterized by severe abdominal pain, vaginal blood loss, uterine contractions, and fetal distress or, even, fetal demise. The prevalence of placental abruption ranges from 3.3 to 11.9 per 1,000 pregnancies and 12.4 per 1,000 twin pregnancies $[3,4]$. Various risk factors are reported, including trauma, hypertension, preeclampsia, maternal age, parity, drug use, smoking, thrombophilia, previous placental abruption, and multiple gestations [5]. Literature on placental abruption in TTTS is limited; the rate of placental abruption in TTTS treated with laser therapy ranges from 1.4 to $5.6 \%$ [6-10]. Two small studies suggest an increased risk of placental abruption after laser therapy with the Solomon technique of 7.9 and $14.0 \%$ compared to 1.4 and $3.1 \%[9,10]$. The objective of this study is to compare the rate of placental abruption in TTTS treated with laser surgery either with the Selective or the Solomon laser technique, and to identify potential risk factors in a large consecutive cohort treated at 2 Fetal Therapy centers in China and The Netherlands.

\section{Methods}

We included all consecutive TTTS-cases treated with fetoscopic laser surgery in the Leiden University Medical Center (LUMC), The Netherlands and in the Shanghai First Maternity and Infant Hospital (SFMIH), China, between January 2002 and January 2020. The SFMIH started with fetoscopy in 2011, and therefore, all cases from this center were treated between January 2011 and January 2020. Cases were excluded when the information on the delivery or used laser technique was not available or when laser therapy was not feasible. Due to geographic differences between The Netherlands and China, we included in China only pregnancies treated and delivered in the SFMIH. In The Netherlands, we included all pregnancies treated and delivered in the LUMC or in a referring partner center if sufficient details of delivery were available. The Research Ethics Board of both participating centers approved the study protocol of this retrospective study.

Fetoscopic laser surgery was performed using a 1.0, 1.3, 2.0, or $3.3 \mathrm{~mm}$ fetoscope (Karl Storz, Tuttlingen, Germany) with a cannula of 8 or 10 French and a 400 or $600 \mu \mathrm{m}$ laser fiber connected to a diode or Nd:YAG laser device (Dornier MedTech, Wessling, Germany). The laser procedure was followed by draining the excessive amniotic fluid to the deepest pocket of $6 \mathrm{~cm} \mathrm{[2].} \mathrm{In} \mathrm{the}$ LUMC, the Selective technique was performed from 2002 to 2012 and the Solomon technique from 2007 to 2020. In the overlapping period from 2007 to 2012, both techniques were performed as this center first conducted a pilot study and then initiated the Solomon trial, comparing the 2 laser techniques. In the SFMIH, the Selective technique was performed between 2011 and 2015, and the Solomon technique between 2015 and 2019. From ultrasound records and discharge letters, we collected the following variables: TTTS stage [11], placental location, gestational age at laser (in weeks), laser technique, energy use (in Joules), maximum power setting (in Watt), duration of the fetoscopy (in minutes), gestational age at birth (in weeks), signs of placental abruption, birth weight (in grams), fetal demise, neonatal survival (survival beyond 28 days after birth), and severe cerebral injury defined as periventricular leukomalacia $\geq$ grade 2 , intraventricular hemorrhage $\geq$ grade 3 , ventricular dilatation $\geq 97$ th percentile, arterial or venous infarction, porencephalic or parenchymal cysts or other severe cerebral lesions $[12,13]$. Two researchers assessed all cases to classify placental abruption. The diagnosis of placental abruption was based on the diagnosis of the obstetrician in the medical record. When the diagnosis of placental abruption was not registered in the medical record by the obstetrician, placental abruption was defined based on 2 clinical observations, an antenatal and a placental/intraoperative observation. Antenatal observations included: excessive vaginal bleeding, severe abdominal pain, uterine hypertonicity, fetal distress, maternal clotting disorder based on consumption coagulopathy, or signs of maternal shock. Placental or intraoperative observations were defined as one of the following: retroplacental hemorrhage on ultrasound, indentation of the placental surface or an unusual amount of clots at placental examination, bloody amniotic fluid, couvelaire uterus or a detached placenta in the setting of caesarean section. Two researchers assessed all cases to classify if the aforementioned criteria were met (P.J.C.K. and F.S.).

The primary outcome was the rate of placental abruption after the Selective laser technique (Selective group) compared to the Solomon technique (Solomon group). Secondary outcomes were the perinatal outcomes of placental abruption cases, the influence of intraoperative conditions as gestational age, energy used, and TTTS stage, on the risk of placental abruption and the rate of placental abruption over time.

\section{Statistical Analysis}

Proportions of laser technique and characteristics were analyzed using a $\chi^{2}$ test or a Fisher's exact test. An association between laser technique and continuous variables was analyzed with a unpaired $t$ test or a Mann-Whitney $\mathrm{U}$ test, according to the distribution of data. Potential risk factors for placental abruption were explored using a univariate logistic regression. The relation between placental abruption and neonatal outcome variables was analyzed using a generalized estimating equation as we considered data of co-twins not independent. The rate of placental abruption over time was compared over the years with a Mantel-Haenszel test for trend. A $p$ value below 0.05 was interpreted as statistically significant. Variables that proved significant in the univariate test were analyzed in the multivariate logistic regression or generalized estimating equation. Statistical analysis was performed using SPSS version 25.0 (IBM Corp., Armonk, NY, USA). 
Table 1. Characteristics of Selective and Solomon technique

\begin{tabular}{|c|c|c|c|c|}
\hline & $\begin{array}{l}\text { Selective technique } \\
(n=289)\end{array}$ & $\begin{array}{l}\text { Solomon technique } \\
(n=441)\end{array}$ & $\begin{array}{l}\text { OR } \\
(95 \% \mathrm{Cl})\end{array}$ & $p$ value \\
\hline Placental abruption, $n$ (\%) & $5(2)$ & $15(3)$ & $0.50(0.18-1.39)$ & 0.184 \\
\hline Laser energy, J & $4,199(2,301-7,891)^{a}$ & $4,943(3,039-7,881)^{b}$ & & 0.123 \\
\hline Duration of fetoscopy, $\min$ & $30(22-40)^{c}$ & $28(20-36)^{d}$ & & 0.015 \\
\hline Maximum laser power & $45(35-50)^{\mathrm{e}}$ & $40(30-50)^{f}$ & & $<0.001$ \\
\hline PPROM <32 weeks, $n$ (\%) & $85(30)^{g}$ & $123(28)$ & $0.92(0.67-1.28)$ & 0.675 \\
\hline Perforation of inter-twin membrane, $n(\%)$ & $57(20)$ & $67(15)$ & $0.74(0.50-1.09)$ & 0.131 \\
\hline Double survival, $n(\%)$ & $176(61)$ & $310(71)^{h}$ & $1.59(1.16-2.18)$ & 0.004 \\
\hline Post-laser TAPS/Recurrent TTS, $n$ (\%) & $37(21)^{c}$ & $24(7)^{i}$ & $0.28(0.16-0.49)$ & $<0.001$ \\
\hline
\end{tabular}

Data are presented as $n$ (\%) or median (interquartile range). OR, odds ratio; $\mathrm{Cl}$, confidence interval; PPROM, preterm premature rupture of membranes; TAPS, twin anemia polycythemia sequence. ${ }^{a}$ Data missing for 109 cases. ${ }^{b}$ Data missing for 86 cases. ${ }^{C}$ Data missing for 112 cases. ${ }^{\mathrm{d}}$ Data missing for 40 cases. ${ }^{\mathrm{e}}$ Data missing for 69 cases. ${ }^{\mathrm{f}}$ Data missing for 57 cases. ${ }^{9}$ Data missing for 1 case. ${ }^{\mathrm{h}}$ Data missing for 6 cases. 'Data are missing for 95 cases.

Fig. 1. Flow diagram of the study popula-

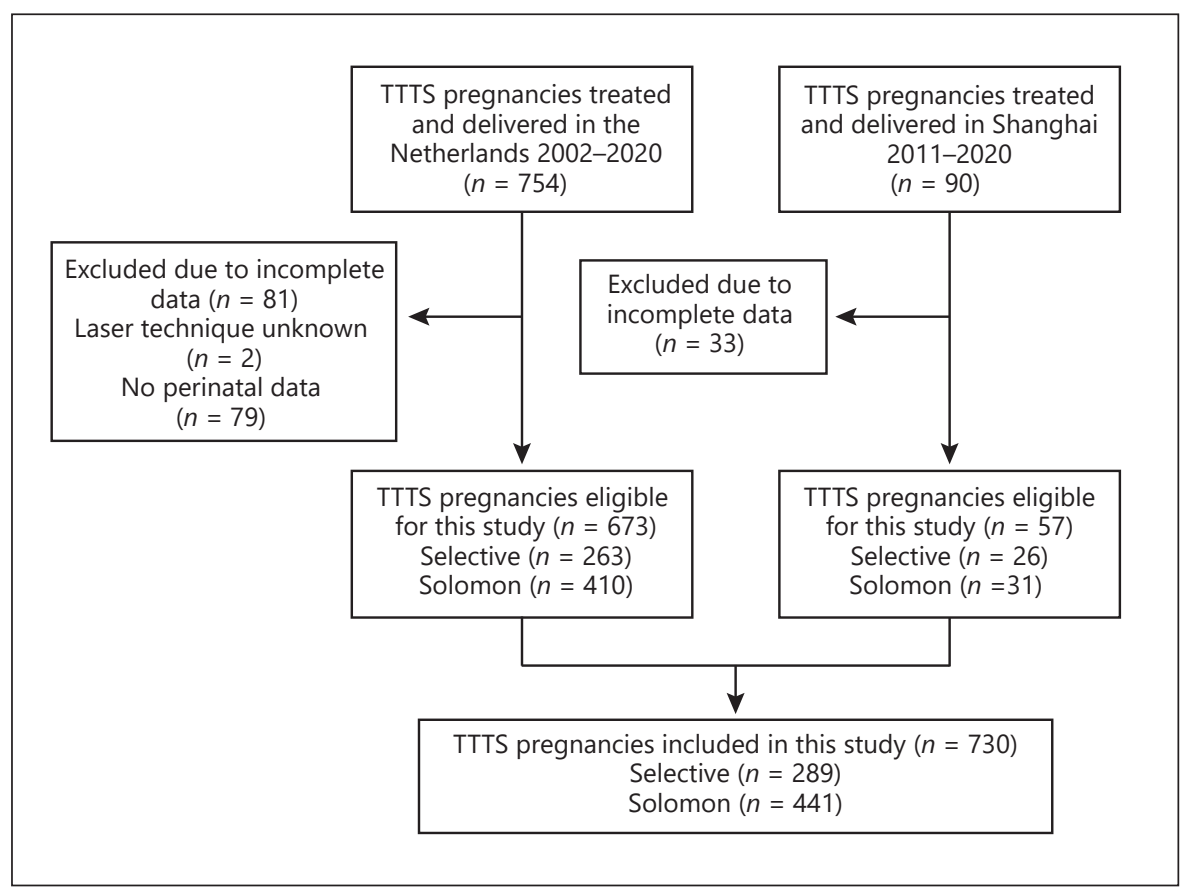

\section{Results}

Between March 2002 and January 2020, 754 pregnancies treated in The Netherlands were eligible for this study (shown in Fig. 1). Perinatal data were missing for 81 pregnancies, mostly from early years and when delivery took place in referring centers. In total, 673 pregnancies were included in this study of which 9 dichorionic triplets and 4 monochorionic triplets. In Shanghai, 217 pregnancies were treated in SFMIH between 2011 and 2019, of which
57 were monitored and delivered in the hospital after the laser surgery and had complete medical records (shown in Fig. 1). The overall prevalence of placental abruption was $2.7 \%(20 / 730)$. The rate of placental abruption in the Selective group was $1.7 \%(5 / 289)$ versus $3.4 \%(15 / 441)$ in the Solomon group (odds ratio [OR] 0.50; 95\% confidence interval $[\mathrm{CI}] 0.18-1.39 ; p=0.184$ ) (shown in Table 1).

Comparing the Selective to the Solomon technique, maximum power use appeared significantly higher and 
Table 2. Characteristics of placental abruption cases

\begin{tabular}{|c|c|c|c|c|}
\hline & $\begin{array}{l}\text { Placental abruption } \\
(n=20)\end{array}$ & $\begin{array}{l}\text { No placental abruption } \\
(n=710)\end{array}$ & $\begin{array}{l}\text { OR } \\
(95 \% \mathrm{Cl})\end{array}$ & $p$ value \\
\hline GA at laser, weeks & $19.0(16.7-20.6)$ & $20.0(17.7-22.9)$ & $0.89(0.77-1.03)$ & 0.124 \\
\hline Placenta located anterior, $n$ (\%) & $10(50)$ & $272(38)$ & $0.62(0.26-1.51)$ & 0.296 \\
\hline \multicolumn{5}{|l|}{ Quintero stage, $n(\%)$} \\
\hline 1 & $2(10)$ & $93(13)$ & Reference & \\
\hline 2 & $7(35)$ & $239(34)$ & $1.36(0.28-6.68)$ & 0.703 \\
\hline 3 & $11(55)$ & $344(48)$ & $1.49(0.32-6.83)$ & 0.610 \\
\hline 4 & $0(0)$ & $34(5)$ & & 0.998 \\
\hline Solomon technique, $n$ (\%) & $15(75)$ & $426(60)$ & $2.00(0.72-5.56)$ & 0.184 \\
\hline Selective technique, $n$ (\%) & $5(25)$ & $284(40)$ & Reference & \\
\hline Energy use, J & $3,567(1,822-5,809)^{a}$ & $4,781(2,780-7,948)^{b}$ & $0.85(0.71-1.02)$ & 0.075 \\
\hline Maximum power use, $\mathrm{W}$ & $45.0(30.0-50.0)$ & $40.0(35.0-50.0)$ & $0.98(0.94-1.02)$ & 0.331 \\
\hline Scopytime, min & $30.0(24.0-36.0)^{c}$ & $30.0(20.0-39.0)^{d}$ & $1.01(0.98-1.04)$ & 0.403 \\
\hline PPROM <32 weeks, $n$ (\%) & $5(25)$ & $203(29)^{\mathrm{e}}$ & $0.83(0.30-2.32)$ & 0.723 \\
\hline
\end{tabular}

Data are presented as $n$ (\%) or median (interquartile range). OR, odds ratio; $\mathrm{Cl}$, confidence interval; GA, gestational age; PPROM, preterm premature rupture of membranes; J, Joules; W, Watt. ${ }^{a}$ Data are missing for 4 cases. ${ }^{b}$ Data are missing for 191 cases. ${ }^{C}$ Data are missing for 3 cases. ${ }^{\mathrm{d}}$ Data are missing for 149 cases. ${ }^{\mathrm{e}}$ Data are missing for 1 case.

Table 3. Perinatal outcome in cases with placental abruption

\begin{tabular}{|c|c|c|c|c|}
\hline & $\begin{array}{l}\text { Placental abruption } \\
\text { ( } n=40 \text { infants) }\end{array}$ & $\begin{array}{l}\text { No placental abruption } \\
\text { ( } n=1,424 \text { infants) }\end{array}$ & $\begin{array}{l}\text { OR } \\
(95 \% \mathrm{Cl})\end{array}$ & $p$ value \\
\hline GA at birth, weeks & $28.5(27.0-31.8)$ & $32.0(29.0-35.0)^{\mathrm{a}}$ & $0.12(0.03-0.49)$ & 0.003 \\
\hline Fetal demise, $n(\%)$ & $5(13)$ & $276(19)$ & $0.56(0.19-1.67)$ & 0.297 \\
\hline Neonatal mortality, $n(\%)$ & $3(9)^{\mathrm{b}}$ & $46(4)^{c}$ & $2.33(0.72-7.50)$ & 0.155 \\
\hline Severe cerebral injury, $n(\%)^{\mathrm{d}}$ & $6(19)^{e}$ & $50(5)^{f}$ & $4.56(1.67-12.45)$ & 0.003 \\
\hline Survival beyond 28 days without cerebral injury, $n(\%)$ & $24(65)^{e}$ & $985(73)^{9}$ & $1.49(0.70-3.21)$ & 0.305 \\
\hline
\end{tabular}

Data are presented as $n$ (\%) or median (interquartile range). OR, odds ratio; $\mathrm{Cl}$, confidence interval; $\mathrm{GA}$, gestational age. ${ }^{\mathrm{a}}$ Data missing for 20 cases. ${ }^{b}$ Data missing for 2 cases. ${ }^{c}$ Data missing for 8 cases. ${ }^{d}$ Defined as $P V L \geq$ grade $2, I V H \geq$ grade 3 , ventricular dilatation, arterial or venous infarction, and other severe cerebral injury. ${ }^{e}$ Data missing for 3 cases. ${ }^{f}$ Data missing for 100 cases. ${ }^{9}$ Data are missing for 81 cases.

the duration of fetoscopy significantly longer when the Selective technique was used, 45 W (IQR 35-50) compared to $40 \mathrm{~W}$ (IQR 30-50) $(p<0.001)$ and $30 \mathrm{~min}$ (IQR $22-40$ ) and $28 \mathrm{~min}$ (IQR 20-36; $p=0.015$ ) respectively. However, maximum power use and duration of fetoscopy were not associated with placental abruption. The median maximum used power was $45.0 \mathrm{~W}$ (IQR 30.0-50.0) in placental abruption cases and 40.0 W (IQR 35.0-50.0) in the group with no placental abruption (OR $0.9895 \% \mathrm{CI}$; $0.94-1.02, p=0.331$ ) (shown in Table 2). Duration of fetoscopy was comparable between the groups with and without placental abruption, respectively $30.0 \mathrm{~min}$ (IQR 24.0-36.0) in the group with placental abruption and 30.0 min (IQR 20.0-39.0) in the group without placental ab-

Placental Abruption after Fetoscopic Laser Surgery in TTTS ruption (OR $1.0195 \% \mathrm{CI} ; 0.98-1.04, p=0.401$ ). Information on used laser energy was available for only 535 cases, due to inconsequent reports of energy use in surgery records (shown in Table 2). The median energy use was 3,567 J (IQR 1,822-5,809) in abruption cases and 4,781 J (IQR 2,780-7,948) in the cases without placental abruption $(p=0.075)$. Placental location, gestational age at laser and TTTS stage were not different between the cases with and without placental abruption. PPROM before 32 weeks gestation was not associated with placental abruption and occurred in 25\% (5/20) of placental abruption cases versus $29 \%(203 / 710)$ overall $(p=0.723)$.

The Solomon technique was associated with a decreased rate of recurrent TTTS or post-laser twin anemia 
polycythemia sequence (OR 0.28 ; 95\% CI $0.16-0.49 ; p<$ $0.001)$ and an higher double survival rate $71 \%(310 / 441)$ compared to $61 \%(176 / 289)(p=0.004)$ (shown in Table 1). Pregnancies complicated by placental abruption delivered at an earlier gestation, 28.5 (IQR 27.0-31.8) weeks compared to 32.0 (IQR 29.0-35.0) weeks (OR 0.12; $95 \%$ CI $0.03-0.49, p=0.003$ ) (shown in Table 3). Severe cerebral injury was detected in 6 of 32 (19\%) surviving children after placental abruption, compared to 50 of $1,048(5 \%)$ surviving children in the group without placental abruption (OR 4.56; 95\% CI 1.67-12.45, $p=0.003$ ). In multivariate analysis, correcting for gestational age at birth, severe cerebral injury was not associated with placental abruption $(p=0.190)$.

When the prevalence of placental abruption was compared between time cohorts of 5 years (2002-2006, 20072011, 2012-2016, 2017-2019), an increasing prevalence was observed from $1.5(2 / 131)$ to $6.1 \%(7 / 114)(p=0.06)$. Double survival rates increased from 56 to $73 \%(p=0.012)$.

\section{Discussion}

We report placental abruption in the largest cohort of TTTS pregnancies treated with fetoscopic laser surgery, to date. The prevalence of this intrauterine complication is $2.7 \%$. We found no significant increased risk of placental abruption in the Solomon group compared to the Selective group.

A recent small study by Lanna et al. [10] reported placental abruption in 3.1\% (9/287) of pregnancies treated with the Selective technique compared to $14.0 \%(12 / 86)$ in the Solomon technique $(p<0.001)$. Concordant with these results, Baschat et al. [9] reported placental abruption in $1.4 \%(1 / 71)$ of TTTS treated with the Selective technique, compared to $7.9 \%(6 / 76)$ in pregnancies treated with the Solomon technique. Both studies have a small sample size and Baschat et al. [9] did not specify their criteria for placental abruption. An association between placental abruption and the Solomon technique was not observed in our study, although placental abruption was more frequently diagnosed in recent years, when the Solomon technique was used. In the period where both techniques were used, no difference in placental abruption was detected. In the previously mentioned studies, the 2 laser techniques were performed subsequently; the Solomon technique was used in the more recent years. The higher prevalence of placental abruption in the Solomon group could therefore merely be an increasing prevalence of placental abruption over time. In addition, we found an increase in double survivors over the years. As more twins are carried for a longer duration of pregnancy, more effort is required of the placenta even as the resistance of the decidual layer weakens. Better short-term survival rates directly after laser surgery could therefore lead to an increased prevalence of later complications. Following a similar course as the increasing PPROM rates described by the study of Stirnemann et al. [14], other explanations of this increasing prevalence over time could be either a relation to an overall increasing prevalence of placental abruption in the general population, as described by Tikkanen [15] in many countries. Or, the increased prevalence is a result of increased awareness, advancement of ultrasound and pathology techniques and improved electronic patient records. Especially the increasing availability of clinical details in patient records, could lead to information bias in retrospective studies.

The prevalence of placental abruption in the overall population ranges from 0.33 to $1.2 \%$ according to a very large study in the United States, Canada, Denmark, Sweden, Spain, Norway, and Finland [16]. Smaller studies in The Netherlands and China report a rate of placental abruption of respectively 0.22 and $0.57 \%[17,18]$. Salihu et al. [3] reported an increased risk of placental abruption in twin $(1.2 \%)$ and triplet (1.6\%) pregnancies compared to singletons $(0.6 \%)$ in the United States. In 2 previous studies in TTTS treated with Selective laser surgery, placental abruption was reported in 1.7-2.2\% [7, 8]. Senat et al. [6] reported placental abruption in $1.4 \%$ of TTTS pregnancies treated with laser and in $2.9 \%$ of TTTS pregnancies treated with amnioreduction. The study by Lanna et al. [10] reported placental abruption in 5.6\% (21/373) of TTTS pregnancies treated with laser therapy versus $1.2 \%$ $(3 / 243)$ in uncomplicated monochorionic twins, excluding selective intrauterine growth restriction. The rate of placental abruption in this study falls in the range of the previously reported rates of $1.4-5.6 \%$ in TTTS treated with laser surgery. This percentage seems slightly higher than the rate in uncomplicated multiple gestations of 1.2$1.6 \%$. If this higher rate is a direct result of the disease or the treatment remains unclear as laser therapy is the preferred treatment and the study of Senat et al. [6] is the only study reporting the rate of placental abruption in TTTS treated otherwise.

If a causal relation exists between TTTS or fetoscopic laser surgery and placental abruption remains, thus, unclear. It is obvious that laser surgery does cause damage to the placental surface. Studies of placental histology after laser surgery are scarce, leading to little knowledge about the tissue damage caused by the laser and the 
deepness of coagulation in the chorionic layers. Akkermans et al. [19] reported an association between the severity of placental damage and PPROM and early delivery. In this study, severe placental damage was associated with a higher total amount of energy use and a lower power setting. A relation between placental damage and placental abruption was not reported. In our study, no association was observed between placental abruption and used laser energy or power settings. The severity of placental damage was not included in this study. Nevertheless, a relation between placental damage and placental abruption possibly exists. To minimalize placental damage, a more superficial coagulation of anastomosis could benefit the placental condition. As hypothesized by Akkermans et al. [19], high power settings could lead to more effective coagulation and consequently, a lower total energy use. Nevertheless, more placenta histology studies are necessary to assess placental damage after laser surgery in relation to complications. This knowledge could help to establish strategies to avoid such complications.

Another remarkable finding is the increased duration of fetoscopy in the Selective technique. This difference could possibly be attributed to a learning curve effect as described by Peeters et al. [20] Duration of fetoscopy was not associated with placental abruption.

In this study, placental abruption was associated with preterm birth resulting in an increased risk of severe cerebral injury. No risk factors for placental abruption were found. Continued research is necessary to understand more about placental abruption in TTTS. Especially, an uniform definition of placental abruption, detailed examination of the placental damage, and standardized prospective recording of data of complications and outcome could improve the knowledge of placental abruption in TTTS.

\section{Strengths and Limitations}

A limitation of this study is the retrospective nature. As placental abruption is a clinical diagnosis, it is most reliably diagnosed by the obstetrician assisting the delivery. Possibly, in some cases, placental abruption may have been misdiagnosed in this study leading to an under- or overestimation. The design of the study made it impossible to completely blind the researchers that collected the data and classified the cases as placental abruption for the used laser technique. In addition, over the years patient records have become more extensive due to advancement in electronic patient systems and better communication with referring centers. This might have led to underdiagnosing in the earlier years in the Selective group. Another limitation is the lack of internationally agreed criteria to diagnose placental abruption, which hampers comparison with other studies. Our definition rests on the opinion of the treating obstetricians as we believe placental abruption is primarily a clinical diagnosis. A previous study reported wide discrepancies between pathological diagnosis of placental abruption and clinical observations [21]. Another limitation is the lack of data on amnion fluid reduction (duration and amount). During laser surgery amniotic fluid of the recipient's, polyhydramniotic sac is routinely drained causing a decrease in uterus size. As a consequence the available surface area of decidua underneath the placenta shrinks, which can potentially lead to placental abruption. A small study in polyhydramnios in singleton pregnancies reported no difference in placental abruption between the group treated with amnioreduction and the untreated group [22]. However, a large study in TTTS treated with laser surgery is necessary to identify whether a possible association between amnioreduction and placental abruption in this group exists. Nevertheless, we present the largest cohort study of placental abruption in TTTS treated with fetoscopic laser surgery to date.

\section{Conclusions}

The rate of placental abruption in TTTS pregnancies treated with fetoscopic laser surgery was $2.7 \%$ and was not associated with the type of laser technique (Selective vs. Solomon technique). We could not identify any risk factors for placental abruption. Continued research in TTTS is necessary to understand potential complications. Therefore, we recommend standardized, prospective recording of complications and outcome after fetoscopy.

\section{Statement of Ethics}

This research complies with the guidelines for human studies and was conducted ethically in accordance with the World Medical Association Declaration of Helsinki. The Research Ethics Board of both participating centers, the Medical Ethics Committee of Leiden-the Hague-Delft, The Netherlands (registration number G20.015), and the Ethics Committee of Tongji University, China (REB registration numbers 2018yxy27) approved the study proto$\mathrm{col}$ of this retrospective study. Due to the retrospective and anonymous data collection, the Ethics Committee exempted this study from obtaining written parental consent. 


\section{Conflict of Interest Statement}

D. Oepkes is an Associate Editor of Fetal Diagnosis and Therapy. All the authors declare that they have no conflicts of interest.

\section{Funding Sources}

There were no funding sources.

\section{Author Contributions}

E.L., J.M.M.v.K., J.M.M., M.C.H., F.J.C.M.K., D.O., L.S. and F.S. participated in conception of the study. P.J.C.K., E.L., and F.S. designed the study and participated in writing the manuscript. P.J.C.K., Y.G., E.L., I.M.S., L.S., and F.S. collected and interpreted data for this study. E.L., Y.G., I.M.S., J.M.M.v.K., J.M.M., M.C.H., F.J.C.M.K., D.O., L.S. and F.S. participated in critically revising the manuscript.

\section{References}

1 Lewi L, Jani J, Blickstein I, Huber A, Gucciardo L, Van Mieghem T, et al. The outcome of monochorionic diamniotic twin gestations in the era of invasive fetal therapy: a prospective cohort study. Am J Obstet Gynecol. 2008 Nov; 199(5):514-8.

2 Slaghekke F, Lopriore E, Lewi L, Middeldorp $\mathrm{JM}$, van Zwet EW, Weingertner A-S, et al. Fetoscopic laser coagulation of the vascular equator versus selective coagulation for twinto-twin transfusion syndrome: an open-label randomised controlled trial. Lancet. 2014 Jun 21;383(9935):2144-51.

3 Salihu HM, Bekan B, Aliyu MH, Rouse DJ, Kirby RS, Alexander GR. Perinatal mortality associated with abruptio placenta in singletons and multiples. Am J Obstet Gynecol. 2005 Jul;193(1):198-203.

4 Ananth CV, Keyes KM, Hamilton A, Gissler $\mathrm{M}, \mathrm{Wu} \mathrm{C}$, Liu S, et al. An international contrast of rates of placental abruption: an ageperiod-cohort analysis. PLoS One. 2015; 10(5):e0125246.

5 Oyelese Y, Ananth CV. Placental abruption. Obstet Gynecol. 2006 Oct;108(4):1005-16.

6 Senat M-V, Deprest J, Boulvain M, Paupe A, Winer N, Ville Y. Endoscopic laser surgery versus serial amnioreduction for severe twinto-twin transfusion syndrome. N Engl J Med. 2004 Jul 8;351(2):136-44.

7 Yamamoto M, El Murr L, Robyr R, Leleu F, Takahashi Y, Ville Y. Incidence and impact of perioperative complications in 175 fetoscopyguided laser coagulations of chorionic plate anastomoses in fetofetal transfusion syndrome before 26 weeks of gestation. Am J Obstet Gynecol. 2005 Sep;193(3 Pt 2):1110-6.
8 Stirnemann JJ, Quibel T, Essaoui M, Salomon LJ, Bussieres L, Ville Y. Timing of delivery following selective laser photocoagulation for twin-to-twin transfusion syndrome. Am J Obstet Gynecol. 2012 Aug;207(2):127-6.

9 Baschat AA, Barber J, Pedersen N, Turan OM, Harman CR. Outcome after fetoscopic selective laser ablation of placental anastomoses vs equatorial laser dichorionization for the treatment of twin-to-twin transfusion syndrome. Am J Obstet Gynecol. 2013 Sep;209(3):234-8.

10 Lanna MM, Faiola S, Consonni D, Rustico MA. Increased risk of placental abruption after solomon laser treatment of twin-twin transfusion syndrome. Placenta. 2017 May; 53:54-6.

11 Quintero RA, Morales WJ, Allen MH, Bornick PW, Johnson PK, Kruger M. Staging of twin-twin transfusion syndrome. J Perinatol. 1999 Dec;19(8 Pt 1):550-5.

12 Levene MI. Measurement of the growth of the lateral ventricles in preterm infants with realtime ultrasound. Arch Dis Child. 1981 Dec; 56(12):900-4

13 de Vries LS, Eken P, Dubowitz LM. The spectrum of leukomalacia using cranial ultrasound. Behav Brain Res. 1992 Jul 31;49(1):16.

14 Stirnemann J, Djaafri F, Kim A, Mediouni I, Bussieres L, Spaggiari E, et al. Preterm premature rupture of membranes is a collateral effect of improvement in perinatal outcomes following fetoscopic coagulation of chorionic vessels for twin-twin transfusion syndrome: a retrospective observational study of 1092 cases. BJOG. 2018 Aug;125(9):1154-62.

15 Tikkanen M. Placental abruption: epidemiology, risk factors and consequences. Acta $\mathrm{Ob}$ stet Gynecol Scand. 2011 Feb;90(2):140-9.
16 Ananth CV, Keyes KM, Hamilton A, Gissler $\mathrm{M}, \mathrm{Wu}, \mathrm{C}$, Liu $\mathrm{S}$, et al. An International Contrast of Rates of Placental Abruption: An Age-Period-Cohort Analysis. PLoS One. 2015;10(5):e0125246.

17 Ye C, Ruan Y, Zou L, Li G, Li C, Chen Y, et al The 2011 survey on hypertensive disorders of pregnancy (HDP) in China: prevalence, risk factors, complications, pregnancy and perinatal outcomes. PLoS One. 2014;9(6): e100180.

18 Ruiter L, Ravelli AC, de Graaf IM, Mol BW, Pajkrt E. Incidence and recurrence rate of placental abruption: a longitudinal linked national cohort study in The Netherlands. Am J Obstet Gynecol. 2015 Oct;213(4):573-8.

19 Akkermans J, de Vries SM, Zhao D, Peeters SHP, Klumper FJ, Middeldorp JM, et al. What is the impact of placental tissue damage after laser surgery for twin-twin transfusion syndrome? A secondary analysis of the Solomon trial. Placenta. 2017 Apr;52:71-6.

20 Peeters SH, Van Zwet EW, Oepkes D, Lopriore E, Klumper FJ, Middeldorp JM. Learning curve for fetoscopic laser surgery using cumulative sum analysis. Acta Obstet Gynecol Scand. 2014 Jul;93(7):705-11.

21 Elsasser DA, Ananth CV, Prasad V, Vintzileos AM. Diagnosis of placental abruption: relationship between clinical and histopathological findings. Eur J Obstet Gynecol Reprod Biol. 2010 Feb;148(2):125-30.

22 Kleine RT, Bernardes LS, Carvalho MA, de Carvalho MH, Krebs VL, Francisco RP. Pregnancy outcomes in severe polyhydramnios: no increase in risk in patients needing amnioreduction for maternal pain or respiratory distress. J Matern Fetal Neonatal Med. 2016 Dec;29(24):4031-4. 